Boise State University

ScholarWorks

Counselor Education Faculty Publications and

Presentations

Department of Counselor Education

$7-1-2014$

\title{
Alcohol-Related Consequences Among First-Year University Students: Effectiveness of a Web-Based Personalized Feedback Program
}

Diana M. Doumas

Boise State University

Kinsey Nelson

Boise State University

Amanda DeYoung

Boise State University

Camryn Conrad Renteria

Boise State University 


\title{
Alcohol-Related Consequences among First Year University Students: Effectiveness of a Web-Based Personalized Feedback Program
}

\author{
Diana M. Doumas* \\ Department of Counselor Education \\ Institute for the Study of Addiction \\ Boise State University \\ dianadoumas@boisestate.edu \\ Kinsey Nelson \\ Department of Counselor Education \\ Institute for the Study of Addiction \\ Boise State University
}

\author{
Amanda DeYoung \\ Department of Counselor Education \\ Institute for the Study of Addiction \\ Boise State University \\ Camryn Conrad \\ Department of Counselor Education \\ Institute for the Study of Addiction \\ Boise State University
}

\begin{abstract}
This study evaluated the effectiveness of a web-based personalized feedback program using an objective measure of alcohol-related consequences. Participants were assigned to either the intervention or an assessment-only control group during university orientation. Sanctions received for campus alcohol policy violations were tracked over the academic year. Results indicated high-risk drinkers in the control group received significantly more sanctions than other students. Results support the effectiveness of web-based interventions.
\end{abstract}

KeyWords: first year students; alcohol; sanctions; web-based; personalized normative feedback

Heavy drinking and alcohol-related consequences represent a significant problem on college and university campuses nationwide. National survey data indicate nearly 70\% of U.S. college and university students report drinking (Johnston, O’Malley, Bachman, \& Schulenburg, 2006) and 40-45\% report engaging in at least one heavy drinking episode in the past two weeks (Wechsler et al., 2002). Research indicates heavy drinking is associated with multiple social and interpersonal problems such as arguing with friends, engaging in unplanned sexual activity, drinking and driving, getting into trouble with the law, and academic difficulties (Abbey, 2002; Cooper, 2002; Hingson, Heeren, Zakocs, Kopstein, \& Wechsler, 2002; Perkins, 2002; Vik, Carrello, Tate, \& Field, 2000; Wechsler , Lee, Kuo, \& Lee, 2000). Additionally, severe consequences such as unintended injuries, sexual and physical abuse, assault, and alcohol-related fatalities have been reported (Center for Science in the Public Interest, 2008; Hingson, Heeren,Winter, \& Wechsler, 2005). These consequences not only affect the individuals involved, but they also have a costly impact on the community.

The National Institute for Alcohol Abuse and Alcoholism has identified first year students as a high-risk group for heavy drinking relative to the general student population (NIAAA, 2002). First year students drink more drinks, engage in heavy drinking episodes more frequently (Turrisi, Padella, \& Wiermsa, 2000), and are more likely to be arrested for alcohol-related incidents (Thompson, Leinfelt, \& Smyth, 2006) in comparison to upperclassmen. This high-risk status afforded to first year students has been attributed to the increase in freedom, decrease in social control, and increase in stress experienced in higher education relative to high-school (Arnett, 2005). Research also indicates leaving home and going to college are significantly related to increases in frequency of alcohol use and heavy episodic drinking (White et al., 2006). Additionally, research indicates increases in drinking may be related to the weakening of parental monitoring and increase in peer relationships (Borsari \& Carey, 2001). This transition is also a time during which students establish their college identity and social system (Borsari, Murphy, \& Barnett, 2007). According to Borsari et al., coping mechanisms, alcohol expectancies, drinking motives, perceived norms, Greek membership, and participation in drinking games all contribute to the increased risk of alcohol use among first-year students. Taken together, these studies suggest that implementing prevention and early intervention 
This is an author-produced, peer-reviewed version of this article. The final, definitive version of this document can be found online at Journal of College Counseling, published by the American Counseling Association. Copyright restrictions may apply. doi: 10.1002/j.21611882.2014.00054.x

strategies, specifically in the first year of college, are crucial to the reduction of negative alcohol-related outcomes. By providing evidence-based programs targeting heavy drinking among first year students, college and university campuses nationwide may experience an overall reduction in alcohol use and the associated negative consequences.

Past interventions implemented within university and college campuses have been based on components from the following three categories: education/awareness programs, cognitive/behavioral skills-based programs, and motivational/feedback-based approaches (Larimer \& Cronce, 2007). Recent reviews of the literature support the efficacy of brief interventions using motivational interviewing and personalized normative feedback for reducing high-risk drinking in university and college students (Carey, Scott-Sheldon, Carey, \& DeMartini, 2007; Larimer \& Cronce). Innovative approaches to implementing brief motivational interventions have also been developed with a growing number of controlled studies indicating that web-based personalized feedback programs are effective in reducing drinking and alcohol-related consequences among college and university students (Carey, Scott-Sheldon, Elliott, Bolles, \& Carey, 2009). By utilizing web-based programs, campuses are able to implement alcohol prevention and intervention programs in a cost effective way. Tech-savvy students are also more receptive to such types of interventions, as web-based programs are less invasive and threatening (Larimer \& Cronce, 2007). In addition, web-based interventions have the potential to be utilized by a variety of individuals and are potentially more engaging for college students who enjoy using the computer and internet.

Evaluating the effectiveness of web-based alcohol programs has become increasingly important with the proliferation of web-based programs used by colleges and universities to address campus alcohol use (Doumas, Kane, Navarro \& Roman, 2011). Although the literature supports the efficacy of providing personalized normative feedback electronically (Carey et al., 2009), only a handful of evaluations have been published supporting the effectiveness of any one program currently available on the market. A growing body of literature supports one such online personalized feedback program, "electronic Check-Up to Go" (e-CHUG, http://www.e-chug.com/). ECHUG was developed by counselors and psychologists at San Diego State University to help motivate students to examine their drinking. Because approximately 550 colleges and universities have adopted e-CHUG (San Diego State University Research Foundation, n.d.), it is important to evaluate the efficacy of this program. To date, four studies have been published specifically evaluating the efficacy of e-CHUG in reducing heavy drinking and alcoholrelated consequences in first year university students (Doumas \& Andersen, 2009; Doumas et al., 2011; Hustad, Barnett, Borsari, \& Jackson, 2010; Walters, Vader, \& Harris, 2007).

In the first controlled trial studying e-CHUG among first year students, Walters and colleagues (2007) evaluated the efficacy of e-CHUG over 16 weeks in a volunteer sample of 106 first year university students reporting heavy episodic drinking. Students were randomly assigned to either e-CHUG or an assessment-only condition. Results at an 8 week follow-up assessment indicated students in the e-CHUG group reduced their reported drinks per week and peak blood alcohol concentration (BAC) relative to the control condition. However, at the 16 week follow-up there were no longer differences between the two groups. Although alcohol-related consequences did decline, there were no differences between the two groups on alcohol-related consequences at either the 8 week or 16 week assessments.

Similarly, Doumas and Andersen (2009) examined the efficacy of e-CHUG in reducing heavy drinking in first year students using a randomized controlled design. However, Author evaluated the effectiveness of e-CHUG incorporated into the curriculum of a first year seminar offered during the spring semester. Results at the 3 month follow-up assessment indicated students classified as high-risk drinkers participating in e-CHUG reduced their weekly drinking quantity, frequency of drinking to intoxication, and number of alcohol-related consequences relative to high-risk students in an assessment-only control condition. Results indicated incorporating e-CHUG into first year activities is a promising strategy for reducing heavy drinking in first year students.

Hustad et al. (2010) also conducted a study aimed at evaluating web-based interventions administered to high-risk college freshmen. First year students were randomly selected and randomly assigned to e-CHUG, AlcoholEdu, a three hour computer-based educational program, or an assessment-only control group. At the one month follow-up, students in both the e-CHUG group and AlcoholEdu group reported less alcohol use than the control group. These results add to the increasing body of literature that supports the effectiveness of web-based interventions, including e-CHUG, in decreasing heavy drinking among first-year university students. 
This is an author-produced, peer-reviewed version of this article. The final, definitive version of this document can be found online at Journal of College Counseling, published by the American Counseling Association. Copyright restrictions may apply. doi: 10.1002/j.21611882.2014.00054.x

Most recently, Doumas and colleagues (2011) evaluated the effectiveness of e-CHUG in reducing heavy drinking and alcohol related-consequences among first year university students who were administered the intervention during their summer orientation. Two orientation sections were randomly assigned to the e-CHUG group or an assessment-only control group. Students were classified as high-risk or low-risk drinkers based on reports of binge drinking at the baseline assessment. Results of the study showed that high-risk students in the e-CHUG group reported a greater reduction in peak drinking, frequency of drinking to intoxication and alcohol-related consequences than participants in the control group at the 3-month follow up. Results supported previous research (Doumas \& Andersen, 2009) indicating that incorporating e-CHUG into first year orientation activities is effective in reducing heavy drinking and the negative associated consequences in first year university students.

Because e-CHUG is being used at so many colleges and universities and is often administered during first year orientation, it is important to add to the literature evaluating e-CHUG as an evidence-based strategy. Findings of previous research provide support for the efficacy of e-CHUG in reducing heavy drinking and alcohol-related consequences in first year students. To date, however, research has only relied on self-report measures to evaluate the efficacy of e-CHUG, and follow-up periods within the studies have been between one to four months. In the most recent e-CHUG evaluation study, Doumas et al. (2011) suggested researchers examine the efficacy of webbased programs using objective measures and longer follow-up periods.

The aim of the current study is to extend the literature by adding to the current evidence supporting e-CHUG in two ways. First, the current study used an objective measure, rather than self-report measure, of alcohol-related consequences to evaluate the effectiveness of e-CHUG. Specifically, the number of alcohol policy violations resulting in university sanctions were tracked among participants from our previous study (Doumas et al., 2011). Second, sanctions were tracked across the academic year, resulting in a longer follow-up period of 10 months. We hypothesized that significantly more students in the control group classified as high-risk drinkers would receive university sanctions than high-risk students in the e-CHUG group and low-risk students in both the e-CHUG and control groups.

\section{Method}

\section{$\underline{\text { Participants and Procedures }}$}

Participants were recruited from two first year summer orientation sections at a large metropolitan university in the Northwest. The orientation sections took place in July and followed a 2-day format. The two orientation sections were randomly assigned by coin toss to either the e-CHUG group or assessment-only control group. All first year students enrolled in the two sections and present during the baseline assessment $(N=350)$ were given an opportunity to participate in the study. Enrollment in first year orientation was voluntary and the program was offered as part of first year orientation activities. All students enrolled in these orientation sections agreed to participate. All participants were informed of the nature of the study, risks and benefits of participation, and information regarding the voluntary nature of participation. Participants were offered a chance to win a \$100 VISA gift card as compensation for their participation. All participants were treated according to established ACA ethical standards (American Counseling Association, 2005) and the research was approved by the University Institutional Review Board.

Three-hundred and fifty students (35\% male; 65\% female) were present at baseline and participated in the study. Of these, $167(48 \%)$ were in the orientation section assigned to the e-CHUG condition and 183 (52\%) were in the orientation section assigned to the assessment only control condition. Ages of the students ranged from 17-19 $(M=$ 18.0, $S D=0.45)$. Ninety percent were Caucasian, $4 \%$ Hispanic, $3 \%$ Asian-American, and $3 \%$ other. A series of chi-square analyses and t-tests confirmed there were no differences between the two groups in gender, age, or ethnicity. A series of t-tests also confirmed there were no baseline differences on any self-reported drinking measures at baseline (see Table 1). Additionally, there were no differences in any of the drinking variables between white students and students of color.

Detailed procedures related to self-report baseline and follow-up measures are detailed in Doumas et al., 2011. Members of the research team joined orientation leaders to facilitate the administration of the baseline assessment and the e-CHUG program during first year orientation activities. Students in both groups were informed that the research team was "interested in helping first year students become more aware of their alcohol-related 
This is an author-produced, peer-reviewed version of this article. The final, definitive version of this document can be found online at Journal of College Counseling, published by the American Counseling Association. Copyright restrictions may apply. doi: 10.1002/j.21611882.2014.00054.x

experiences." Students assigned to the intervention group were told, "As part of orientation, you are invited to participate in this process by completing the following survey and self-assessment known as e-CHUG (electronic Check-Up to Go). The survey consists of a list of questions regarding alcohol use patterns. e-CHUG is an interactive web assessment that allows college students to enter information about their drinking patterns and receive feedback about their use. Your personalized feedback and comparison to national and Boise State University norms is displayed in an easy-to-read format upon completion of the assessment." Students assigned to the assessmentonly condition were told, "As part of orientation, you are invited to participate in this process by completing the following survey. The survey consists of a list of questions regarding alcohol use patterns." Students in the e-CHUG condition group completed the baseline assessment and the e-CHUG program during orientation activities. Students in the assessment-only control group completed the baseline assessment only and did not complete an alternative neutral intervention. University sanctions for campus alcohol policy violations received by participants were tracked and recorded from August through May.

\section{$\underline{\text { Instruments }}$}

Alcohol-related consequences. Alcohol-related consequences were measured by tracking university sanctions for violating the campus alcohol policy. Campus alcohol policy violations were defined by the university as a violation that may include, but not limited to possession, consumption, or distribution of alcoholic beverages. Students violating the campus alcohol policy received a sanction which included a referral to the campus counseling center for evaluation and a $\$ 25$ fee. The number of participants in each study group who received a sanction was tabulated from August through May.

Classification of risk status. Following the Harvard School of Public Health College Alcohol Study (CAS), binge drinking was defined as having 5 or more drinks in a row for males (4 or more for females) (Wechsler et al., 1994). This item was used as an indicator of high-risk drinking and was used to create a risk variable, with participants indicating one or more occasions of binge drinking in the past 2 weeks at the baseline assessment classified as highrisk drinkers. The 5/4 binge drinking measure has been widely used and supported as an appropriate threshold to identify high-risk drinkers (Wechsler \& Nelson, 2001; 2006) and identified as a dangerous level of drinking (NIAAA, 2004). Using this measure, $27 \%$ of the participants were classified as high-risk drinkers and $73 \%$ were classified as low-risk drinkers.

\section{$\underline{\text { Intervention }}$}

Students in the intervention group were directed to take e-CHUG, a National Association of Student Personnel Administrators (NASPA) recognized, evidenced-based, online alcohol intervention and personalized feedback tool developed by counselors and psychologists at San Diego State University. This brief web-based program is designed to reduce high-risk drinking by providing personalized feedback and normative data regarding drinking and the risks associated with drinking. The program is commercially available and is managed by the San Diego State University Research Foundation. Further details about the program, procedures and costs for subscribing to the program, and supporting research are provided on the program website (http://www.e-chug.com/). The e-CHUG program is customized for the participating college or university, including providing normative data for the specific university population, referrals for the local community, and designing the website using university colors and logos. Therefore, e-CHUG is appropriate for all types of colleges and universities, including non-residential campuses, as the normative data are created from data provided by the specific college or university. The e-CHUG program was selected for several reasons including the ability to customize normative data for our university, the focus on personalized feedback, the length of the program, and the cost of the program.

The personalized feedback program takes approximately 30 minutes to complete. Students first complete an online assessment. This assessment consists of basic demographic information (e.g. sex, age, weight, living situation, class standing) and information on alcohol consumption, drinking behavior, and alcohol-related consequences. Immediately following the assessment, individualized graphed feedback is provided in the following domains: Summary of quantity and frequency of drinking including graphical feedback such as the number of cheeseburgers that are equivalent to alcohol calories consumed, graphical comparison of one's own drinking to U.S. adult and college drinking norms, estimated risk-status for negative consequences associated with drinking and risk-status for 
This is an author-produced, peer-reviewed version of this article. The final, definitive version of this document can be found online at Journal of College Counseling, published by the American Counseling Association. Copyright restrictions may apply. doi: 10.1002/j.21611882.2014.00054.x

problematic drinking based on the participant's Alcohol Use Disorder Identification Test (AUDIT) score, genetic risk, tolerance, approximate financial cost of drinking in the past year, normative feedback comparing one's perception of peer drinking to actual university drinking normative data, and referral information for local agencies.

\section{Results}

All analyses were performed using SPSS Version 18.0. A two-way contingency table analysis utilizing a chi-square test of independence was performed to examine significant differences between the number of students receiving sanctions (yes; no) across the four groups of students (low-risk control; high-risk control; low-risk e-CHUG; highrisk e-CHUG). Results of the chi-square analysis indicated a significant relationship between university sanctions and group, $\chi^{2}(3)=10.89, p=0.01$. As hypothesized, results indicated that significantly more high-risk students in the control group received university sanctions relative to the other groups of students. As seen in Table 2, a greater percentage of high-risk students in the control group (11.1\%) received sanctions in comparison to the percentage of high-risk students in the e-CHUG group (2.5\%), low-risk students in the control group (2.2\%) and low-risk students in the e-CHUG group (1.6\%). Further, the majority of students receiving sanctions were high-risk students in the control group (45.5\%), compared to 9.1\% received by high-risk students in the e-CHUG group.

We also conducted a 2 x 2 analysis of variance (ANOVA) to examine mean differences in sanctions between the eCHUG group and assessment-only control group. The two independent variables were Group (e-CHUG; control) and Risk-Status (high-risk; low-risk). Means for sanctions by group and risk-status are shown in Table 3. Results of the ANOVA indicated a significant main effect for Group, $F(1,346)=4.56, p<.03$, a significant main effect for Risk, $F(1,346)=5.23, p<.02$, and an interaction effect approaching significance for the Group $\mathrm{x}$ Risk-Status interaction, $F(1,346)=3.45, p<.06$. Findings indicate that students in the control group received significantly more sanctions than those in the e-CHUG group, particularly among high-risk students.

\section{Discussion}

The aim of this study was to evaluate the effectiveness of a web-based personalized feedback program (e-CHUG) in decreasing alcohol-related consequences among first year university students. Although e-CHUG has been adopted by over 550 colleges and universities nationwide (San Diego State University Research Foundation, n.d.), to date, there are only four published studies providing evidence to support the efficacy of e-CHUG in first year students (Doumas \& Andersen, 2009; Doumas et al., 2011; Hustad et al., 2010; Walters et al., 2007). This is the first study, however, to examine the efficacy of e-CHUG using an objective measure of alcohol-related consequences. Additionally, this study extends the follow-up period to 10 months, more than twice as long as previous studies, which have only followed students for up to 4 months. Thus, the current study adds to the growing body of literature supporting the efficacy of web-based normative feedback programs and provides evidence specifically for the effectiveness of the e-CHUG intervention for first year students.

Findings confirmed the hypothesis that significantly more high-risk student in the control group would receive university sanctions for campus alcohol policy violations than students in the other groups across the academic year. Eleven percent of high-risk students in the control group received university sanctions compared to $2.5 \%$ of the high-risk students in the e-CHUG group, $2.2 \%$ of low-risk students in the control group, and $1.6 \%$ of low-risk students in the e-CHUG group. Additionally, $45.5 \%$ of sanctioned students among study participants were in the high-risk control group, compared to only $9.1 \%$. in the high-risk e-CHUG group. Additionally, results from the ANOVA indicted that students in the assessment-only control group received more sanctions than those in the eCHUG group, and this was particularly true for high-risk students. Results of this study are consistent with research indicating e-CHUG is effective in reducing drinking (Doumas \& Andersen, 2009; Doumas et al., 2011; Hustad et

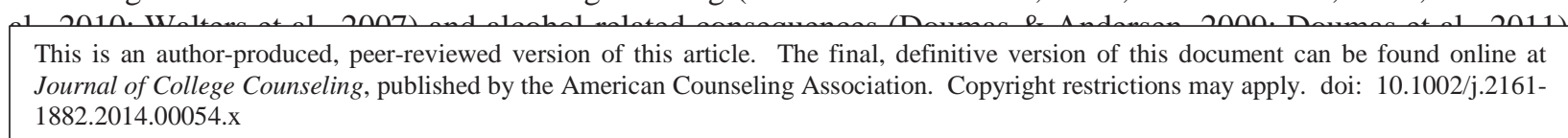

Results of this study have important implications for prevention and intervention efforts aimed at reducing drinking and alcohol-related consequences for first year college and university students. First, $27 \%$ of this sample was classified as high-risk drinkers, indicating approximately one third of the students in this sample reported binge drinking at least once in the past 2 weeks prior to the baseline survey. Additionally, high-risk students in the control group received sanctions throughout the academic year. Coupled with prior research indicating first year students 
increase their alcohol use over the academic year (Borsari et al., 2007) and are at risk for alcohol-related consequences throughout the academic year (Doumas \& Andersen, 2009), findings from this study confirm that counselors need to remain aware that drinking may become heavier and more alcohol-related consequences may occur as the academic year progresses (Doumas et al., 2011).

According to Doumas et al. (2011), web-based programs such as e-CHUG should be incorporated into a comprehensive strategy to address student drinking including community, campus environment, and individual-level programs. Although web-based personalized feedback is cost-effective and easy to disseminate to large groups of students, this strategy may not be effective for all students. Additional environmental strategies, such as community and campus alcohol policies targeting responsible drinking, need to be implemented. Thus, web-based feedback programs should be viewed as part of a larger, overall campus strategy to reduce heavy drinking and the associated consequences.

\section{Limitations and Directions for Future Research}

Although this study provides additional empirical support for web-based personalized feedback programs in general, and e-CHUG in particular, there are several limitations. First, the sample in this study was 90\% Caucasian. Because of the primarily Caucasian composition of the sample, generalizability of the results from this study is limited to this population. In addition, research indicates different patterns of drinking across ethnic groups with Caucasian students reporting the highest prevalence of heavy drinking in college, followed by Hispanic and Black students, respectively (O'Malley \& Johnston, 2002), although students of color report more alcohol-related problems (Taylor, Johnson, Voas, \& Turrisi, 2006). Therefore, future research with more diverse samples is recommended to assess whether or not the findings in this study generalize to students from other ethnic backgrounds.

The second limitation is related to our recruitment strategy. First year students were recruited from two orientation sections. Students enrolled in orientation may be different from general college or university first year students, as orientation was voluntary and may have attracted a particular type of student. Additionally, because of logistics in implementing this evaluation as part of the first year orientation, orientation sections, rather than first year students, were randomly assigned to the two conditions. Lack of random assignment may lead to initial differences between groups which may impact the validity of findings. Examination of demographic variables and drinking measures, however, revealed no baseline differences between the two groups, thus mitigating the problem of non-random assignment. In future studies, however, random assignment of individual students, rather than orientation sections should be conducted.

Additionally, although this study extends the literature by using an objective measure of alcohol-related consequences, it should be noted that not all campus policy violations are detected and not all campus policy violations are reported. Therefore, not all students who violate the campus alcohol policy receive a sanction. Data in the study are based on reported violations, and therefore, may underestimate the number of violations that occurred in this participant sample across the academic year. The likelihood of "getting away with" a policy violation, however, should be similar across the study groups.

\section{Conclusions}

Research has identified first year university students as being at-risk for heavy alcohol consumption and increased negative alcohol-related consequences. Despite prevention efforts, however, first year students remain a high-risk population for alcohol-related consequences on college and university campuses. Results of this study add to the

This is an author-produced, peer-reviewed version of this article. The final, definitive version of this document can be found online at Journal of College Counseling, published by the American Counseling Association. Copyright restrictions may apply. doi: 10.1002/j.21611882.2014.00054.x

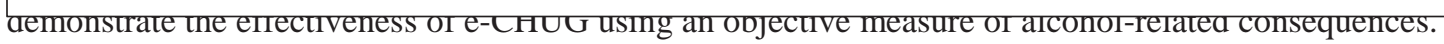

Because of the low cost, ease of dissemination, and growing empirical evidence associated with web-based personalized normative feedback, this type of program is ideal for colleges and universities without many resources, needing to target large numbers of students, or wanting to provide students unlimited program access across the academic year (Doumas et al., 2011). Furthermore, web-based interventions are able to reach a larger population with minimal resources required. Directions for future research include examining the impact of web-based 
personalized feedback programs with a more diverse sample and with other high-risk groups, such as fraternity and sorority members. Further, additional objective outcome measures, such as academic success (e.g. retention rate or grade point average), could be included as measures of program effectiveness. Finally, including all first year students in a randomized controlled study using objective outcome measures and a long-term follow-up would strengthen the support for the efficacy of web-based interventions for first year students.

\section{References}

Abbey, A. (2002). Alcohol-related sexual assault: A common problem among college students. Journal of Studies on Alcohol, Supplement, 14, 118-128.

American Counseling Association (2005). ACA Code of Ethics. Alexandria, VA: Author.

Arnett, J. J. (2005). The developmental context of substance abuse in emerging adulthood. Journal of Drug Issues, $35,235-254$.

Borsari, B., \& Carey, K. B. (2001). Peer influences on college drinking: A review of the research. Journal of Substance Abuse, 13, 391-424.

Borsari, B., Murphy, J. G., \& Barnett, N. P. (2007). Predictors of alcohol use during the first year of college: Implications for prevention. Addictive Behaviors, 32, 2062-2086.

Carey, K. B., Henson, J. M., Carey, M. P., \& Maisto, S. A. (2009). Computer versus in-person intervention for students violating campus alcohol policy. Journal of Consulting and Clinical Psychology, 77, 74-87.

Carey, K. B., Scott-Sheldon, L. A. J., Carey, M. P., \& DeMartini, K. S. (2007). Individual-level interventions to reduce college student drinking: A meta-analytic review. Addictive Behaviors, 32, 2469-2494.

Carey, K. B., Scott-Sheldon, L. A. J., Elliott, J. C., Bolles, J. R., \& Carey, M. P. (2009) Computer delivered interventions to reduce college student drinking: A meta-analysis. Addiction, 104, 1807-1819.

Center for Science in the Public Interest. (2008). Alcohol policy: Binge drinking on college campuses. Retrieved May 29, 2009, from http://www.cspinet.org/alcohol/index.html.

Cooper, M. L. (2002). Alcohol use and risky sexual behavior among college students and youth: Evaluating the evidence. Journal of Studies on Alcohol, Supplement, 14, 101-117.

Doumas, D. M., \& Andersen, L. L. (2009). Reducing alcohol use in first-year university students: Evaluation of a web-based personalized feedback program. Journal of College Counseling, 12, 18-32.

Doumas, D. M., Kane, C. M., Navarro, T. B., \& Roman, J. (2011). Decreasing heavy drinking in first year students: Evaluation of a web-based personalized feedback program administered during orientation. Journal of College Counseling, 14, 5-20.

Hingson, R. W., Heeren, T., Winter, M., \& Wechsler, H. (2005). Magnitude of alcohol-related mortality and morbidity among U.S. college students ages 18-24: Changes from 1998-2001. Annual Review of Public Health, 26, 259-279.

Hingson, R. W., Heeren, T., Zakocs, R. C., Kopstein, A., \& Wechsler, H. (2002). Magnitude of alcohol-related mortality and morbidity among U.S. college students ages 18-24. Journal of Studies on Alcohol, 63, 136144.

Hustad, J. T. P., Barnett, N. P., Borsari, B., \& Jackson, K. M. (2010). Web-based alcohol prevention for incoming college students: A randomized controlled trial. Addictive Behaviors, 35, 183-189.

Johnston, L. D., O'Malley, P. M., Bachman, J. G., \& Schulenberg, J. E. (2006). Monitoring the future national survey results on drug use, 1975-2005. Volume II: College students and adults ages 19-45. Bethesda, MD: National Institute on Drug Abuse.

Larimer, M. E., \& Cronce, J. M. (2007). Identification, prevention, and treatment revisited: Individual-focused college drinking prevention strategies 1999-2006. Addictive Behaviors, 32, 2439-2468.

National Institute on Alcohol Abuse and Alcoholism (2002). A call to action: Changing the culture of drinking at U.S. colleges. Washington D.C: National Institutes of Health.

National Institute on Alcohol Abuse and Alcoholism (2004). National Institute of Alcohol Abuse and Alcoholism Council approves definition of binge drinking. NIAAA Newsletter, 3:3.

O’Malley, P. M., \& Johnston, L. D. (2002). Epidemiology of alcohol and other drug use among American college students. Journal of Studies on Alcohol, Suppl., 14, 23-29.

Perkins, H. W. (2002). Social norms and the prevention of alcohol misuse in collegiate contexts. Journal of Studies on Alcohol, Supplement, 14, 164-172.

San Diego State University Research Foundation (n.d.). e-CHUG on www.e-CHUG.com. 
This is an author-produced, peer-reviewed version of this article. The final, definitive version of this document can be found online at Journal of College Counseling, published by the American Counseling Association. Copyright restrictions may apply. doi: 10.1002/j.21611882.2014.00054.x

Taylor, D. M., Johnson, M. B., Voas, R. B., \& Turrisi, R. (2006). Demographic and academic trends in drinking patterns and alcohol-related problems on dry college campuses, Journal of Alcohol and Drug Education, 50(4), 35-54.

Thompson, K. M., Leinfelt, F. H., \& Smyth, J. M. (2006). Self-reported official trouble and official arrest: Validating a piece of the core alcohol and drug survey. Journal of Substance Use, 11, 23-26.

Turrisi, R., Padella, K. K., \& Wiersma, K. A. (2000). College student drinking: An examination of theoretical models of drinking tendencies in freshmen and upperclassmen. Journal of Studies on Alcohol, 61, 598-602.

Walters, S. T., Vader, A. M., \& Harris, T. R. (2007). A controlled trial of web-based feedback for heavy drinking college students. Prevention Science, 8, 83-88.

Wechsler, H., Davenport, A., Dowdall, G., Moeykens, B., \& Castillo, S. (1994). Health and behavioral consequences of binge drinking in college: A national survey of students at 140 campuses. Journal of the American Medical Association, 272, 1672-1677.

Wechsler, H., Lee, J. E., Kuo, M., \& Lee, H. (2000). College binge drinking in the 1990s: A continuing problem. Results of the Harvard School of Public Health 1999 College Alcohol Study. Journal of American College Health, 48, 199-210.

Wechsler, H., Lee, J. E., Kuo, M., Seibring, M., Toben, N., \& Lee, H. (2002). Trends in college binge drinking during a period of increased prevention efforts. Journal of American College Health, 50, 203-217.

Wechsler, H., \& Nelson, T. F. (2001). Binge drinking and the American college student: What's five drinks? Psychology of Addictive Behaviors, 15, 287-291.

Wechsler, H., \& Nelson, T. F. (2006). Relationship between level of consumption and harms in assessing drink cutpoints for alcohol research: on "Many college freshmen drink at levels far beyond the binge threshold" by White et. al. Alcoholism: Clinical and Experimental Research, 30, 922-927.

White, H. R., McMorris, B.J., Catalano, R. F., Fleming, C. B., Haggerty, K. P., \& Abbott, R. D. (2006). Increases in alcohol and marijuana use during the transition out of high school into emerging adulthood: The effects of leaving home, going to college, and high school protective factors. Journal of Studies on Alcohol, 67, 810822.

Vik, P. W., Carrello, P., Tate, S. R., \& Field, C. (2000). Progression of consequences among heavy-drinking college students. Psychology of Addictive Behaviors, 14, 91-101. 
This is an author-produced, peer-reviewed version of this article. The final, definitive version of this document can be found online at Journal of College Counseling, published by the American Counseling Association. Copyright restrictions may apply. doi: 10.1002/j.21611882.2014.00054.x

Table 1

Means and Standard Deviations of Drinking Variables by Group at Baseline

$\begin{array}{lc}\text { Control Group } & \text { e-CHUG Group } \\ (n=183) & (n=167)\end{array}$

Mean $\quad$ SD $\quad$ Mean $\quad$ SD

Peak Drinking

3.59

5.02

4.23

5.48

Drinking to Intoxication

0.70

1.23

0.70

1.14

Weekly Drinking

2.73

5.29

3.06

5.53

Alcohol-Related Consequences

1.66

2.75

1.69

2.66

Table 2

Frequencies and Percentages of Students Receiving Sanctions by Group

Control Group

e-CHUG Group

\begin{tabular}{|c|c|c|c|c|}
\hline & High-Risk & Low-Risk & High-Risk & Low-Risk \\
\hline Received Sanction & $(n=45)$ & $(n=138)$ & $(n=40)$ & $(n=127)$ \\
\hline
\end{tabular}

$\begin{array}{lcccc}\text { Number of Students } & 5 & 3 & 1 & 2 \\ \text { Percent within Group } & 11.1 \% & 2.2 \% & 2.5 \% & 1.5 \% \\ \text { Percent within Sanctions } & 45.5 \% & 27.3 \% & 9.1 \% & 18.2 \%\end{array}$


This is an author-produced, peer-reviewed version of this article. The final, definitive version of this document can be found online at Journal of College Counseling, published by the American Counseling Association. Copyright restrictions may apply. doi: 10.1002/j.21611882.2014.00054.x

Table 3

Means and Standard Deviations of Sanctions by Group and Risk Status and Risk-Status

Control Group
e-CHUG Group

$\begin{array}{llll}\text { High-Risk } & \text { Low-Risk } & \text { High-Risk } & \text { Low-Risk } \\ (n=45) & (n=138) & (n=40) & (n=127)\end{array}$

Mean (SD)

$0.11(.32)$

$0.02(.14)$

$0.03(.16)$

$0.02(.13)$ 